\title{
Historical profile and perspectives in Oncology
}

\author{
Maria Aparecida Azevedo Koike Folgueira
}

A lthough our medical school has been created more than a century ago, clinical oncology, as an organized and comprehensive discipline, has a relatively recent history. For a long time, education in clinical oncology was spread through various clinical and surgical disciplines in the undergraduate curriculum from Faculdade de Medicina da Universidade de São Paulo FMUSP. In accordance, at Hospital das Clínicas (HC) da FMUSP, patient care in clinical oncology was given by medical doctors from a large gamma of specialties, as well as by radiotherapists and hematologists. In our school, the dawn of Oncology may be associated with professionals involved in these areas as well as with biochemistry and pathology.

During the years, there was a lot of debate about the introduction of Oncology as a discipline in FMUSP, as well as an Oncology Unit, to treat patients. In 1963, the creation of the Oncology Center (Centro de Oncologia, CEON) was approved, then, in 1968, an Administrative Council was set, and afterwards, in 1971, a location, the old Biothery building, was decided. At the same period, in 1970, following the academic reform, the Biochemistry discipline, including Prof. Ricardo Brentani and Prof. Mitzi Brentani, was transferred to the University main campus, along with other basic disciplines of the medical curriculum. In 1973, the creation of the Department of Oncology was proposed by Prof Charles Corbett, including two disciplines: Community Oncology and Cellular and Experimental Oncology. Afterwards, in 1974-1975, a huge initiative gave rise to the implementation of the "Laboratories of Medical Investigation" (Laboratórios de Investigação Médica, LIM), including the Lab of Experimental Oncology, chaired by Prof Ricardo Brentani and co-chaired by Prof Mitzi, and a few years later, in 1980, Prof Brentani assumed the recently created Chair of Oncology, as a full professor (Prof titular de Terapêtica Clínica II-Oncologia) from the Department of Clinical Medicine. As a result, faculty members from the Oncology discipline were invited to teach topics in Oncology in the Pathology undergraduate course. This was the embrio of an undergraduate course, totally dedicated to Clinical Oncology, introduced in the medical curriculum some years later, in 1994. In addition, a graduate "stricto sensu" program, with master and $\mathrm{PhD}$ degrees, was established in 1989. During this period, oncology care at Hospital das Clínicas was not centralized and cancer patients were treated in many different clinical services, according to tumor primary site, except for radiotherapy and systemic therapy, which were administered at Instituto de Radiologia and chemotherapy room, at Prédio dos Ambulatórios $\left(6^{\text {th }}\right.$

Associated Professor of the Department of Radiology and Oncology, University of São Paulo, School of Medicine.

Mailing address: Maria Aparecida A. Koike Folgueira. Faculdade de Medicina. Av. Dr. Arnaldo, 455, sala 4117. 01246-903 São

Paulo, SP, Brazil. Email: maria.folgueira@fm.usp.br 
floor), respectively. Consequently, in 1994, hospital services of Clinical Oncology and Radiotherapy were united in the newly created Radiology Institute (Instituto de Radiologia -INRAD) and Radiology Department. Afterwards, medical residency in Clinical Oncology was established in 1998, with two places per year and at last, in 2006, the Oncology Center, beside INRAD, was inaugurated by Gov. Cláudio Lembo. By this time, FMUSP had a complete education program in Oncology.

Prof Brentani, retired in 2007, was the first full professor in Oncology in Brazil and the Oncology discipline at FMUSP was the first comprehensive undergraduate course and graduate program introduced in our country. In this mission, Prof Brentani counted on the collaboration of Prof Mitzi, Prof Miriam Hatue Honda Federico, Prof Roger Chammas, Prof Maria Aparecida Azevedo Koike Folgueira, Dr. Maria del Pilar Estevez Diz, Dr. Igor Snitcovsky, Prof. Maria Aparecida Nagai and Prof Shigueko Sonohara Troyano Pueyo.

But then a new chapter began with new protagonists.

The number of cancer patients kept on growing demanding a state government intervention to improve patient care. In a huge effort of Governor José Serra and Faculty members of FMUSP, including Prof Giovanni Guido Cerri, Prof Paulo Marcelo Gehm Hoff and Prof. Roger Chammas, the skeleton of the building planned to house the Women Institute gave rise to the 28 floors of the Cancer Institute (Instituto do Câncer do Estado de São Paulo, ICESP), inaugurated in 2008, and nowadays the largest hospital in Latin America, totally dedicated to cancer care. ICESP allowed the integration of health professionals from the system Hospital das Clinicas - FMUSP, involved in cancer treatment, in an innovative concept of care delivery, benefitting patients, who may have all stages of their care, from diagnosis to rehabilitation, in the same location. Recognizing the advantage of such approach, only a few years after its inauguration, ICESP was ranked $1^{\text {st }}$ place in a satisfaction opinion research, performed among patients from hospitals from the Brazilian Unified Health System (Sistema Único de Saúde, SUS), sponsored by São Paulo State Health Secretary (Secretaria de Estado da Saúde, SES) in 2011. ICESP, with 499 hospital beds, 85 intensive care unit (ICU) beds, 107 chemotherapy chairs, was the stage in 2013 of 202,064 medical appointments, 8,277 surgeries, 54,707 chemotherapy sessions and 59,401 radiotherapy sessions. In connection with these facts, there was a renewed interest in Oncology residency, and the number of new places grew to 14 per year. Nowadays, ICESP is one of the main training centers In Oncology in Brazil and our ex-residents are spread all over the national territory.

Following the university main focus in education, research and community care, in 2011, the Translational Center for Oncology Investigation (Centro de Investigação Translacional em Oncologia, CiTO), was inaugurated on the $8^{\text {th }}$ floor of ICESP, with research laboratories and multi-user equipment facilities, regarding all the main up to date techniques used in biomarkers research, molecular oncology, therapeutic innovation, including pre-clinical to clinical research areas. Moreover, the creation of the Biobank will allow a boost in translational research in the next few years.

In oncology, we may say that professors and researchers from FMUSP-ICESP-CTO are leaders in clinical and translational research. This activity translates in the attraction of clinical trials and cooperative studies for the center, with a direct impact in patient care, who may have access to innovative treatments. Concerning public policies we can mention the pioneering work "Manual of procedures in Oncology - Manual de Condutas em Oncologia" edited by members of USP Oncology Discipline and medical doctors from ICESP, aimed at guidance on clinical treatment of cancer patients. This manual, based on medical literature, firstly published in 2003 and rewritten periodically thereafter, was endorsed by the Secretary of Health from São Paulo State, in order to direct the access of any patient to molecular therapy.

What about the future? Patients are having a good standard of care and having the opportunity to engage in clinical trials, in cancer prevention and early detection programs, and a research network is already in place. Although a remarkable progress has been achieved, cancer is still an important cause of mortality and morbidity. Nevertheless, more cancer patients are expected in the years to come, as life expectancy increases and other chronic diseases are better controlled.

But the horizon seems to get clearer in the Oncology area. Cancer heterogeneity is a challenge that may be 
partly solved through next generation sequencing of tumor genomes. New targets will fuel the cancer tailored treatments. Fresh tumor engraftment and expansion in animals will allow targeted therapies to be tested for each individual tumor. In addition, the development of more precise robotic surgical devices will allow less traumatic surgeries and nanotechnology will enable the development of new ways to deliver drugs more effectively to cancer cells.

In the last 100 years, from the mustard gas, used on the trenches of the I World War, the first chemotherapy agent was developed. For the next 100 years we can preview a new era on cancer treatment based on tumor targets and personalized treatment.

Acknowledgments: Prof. Dr. André Mota, Coordinator of the "Museu Histórico da FMUSP - Carlos da Silva Lacaz".

\section{REFERÊNCIAS}

American Cancer Society. The history of cancer [cited 2015 Oct]. Available from: http://www.cancer.org/cancer/cancerbasics/ thehistoryofcancer/the-history-of-cancer-what-is-cancer.

Contratos e convênios. FFM continua à frente da gestão do ICESP. J FFM. 2014 jul.-ago.;13(74).

Instituto do Câncer do Estado de São Paulo (ICESP). Histórico [cited Oct 2015]. Available from: http://www.icesp.org.br/
Institucional/Sobre-o-Icesp/Hist $\% \mathrm{C} 3 \% \mathrm{~B} 3 \mathrm{rico} /$.

Belarmino A. Departamento de Radiologia. In: Mota A, Marinho MGSMC, organizadores. Trajetória da FAculdade de Medicina da Universidade de São Paulo - aspectos históricos da Casa de Arnaldo (departamentos da Faculdade de Medicina da Universidade de São Paulo). São Paulo: CD.G Casa de Soluções e Editora; 2012. v.2, p.264-83. 